\title{
Peroral extrusion of ventriculoperitoneal shunt: Case report and review of literature
}

\author{
K. Sridhar, Vikram Karmarkar \\ Department of Neurosurgery, National Neurosciences Centre, Kolkata, India
}

\author{
Address for correspondence: \\ Dr. K. Sridhar, \\ Department of Neurosurgery, \\ National Neurosciences Centre, \\ Peerless Hospital II Floor, 360, \\ Panchasayar, Kolkata - 700094 , \\ India. \\ E-mail: neuro_sridhar@hotmail.com
}

DOI: $10.4103 / 0028-3886.53283$

\begin{abstract}
A rare complication of ventriculoperitoneal shunting (VPS) is bowel perforation by the peritoneal catheter of the shunt tube. Rarer still is the peroral extrusion of such a perforated shunt. A two-month-old infant with history of neonatal meningitis, presented with a large head, bulging fontanelle, and hydrocephalus. A VPS was inserted. The child was doing well till the age of eight months, when following vomiting, the peritoneal end of the shunt came out through the mouth. The shunt was removed and antibiotics started. At follow up after 12 months, the child was doing well. Peroral extrusion of the shunt tube needs prompt treatment, including removal of the extruded shunt tube, and attention to bowel perforation and possible cerebrospinal fluid infection. The reported patient is younger than the five cases reported earlier. Strategies in the management of this complication are reviewed. An individualized approach is essential for the successful treatment of this rare complication.
\end{abstract}

Key words: Bowel perforation, complications, hydrocephalus, oral extrusion, ventriculoperioneal shunt

\section{Introduction}

While ventriculoperitoneal shunt (VPS) is a standard operative procedure for hydrocephalus, complication rates between 24 and $47 \%$ have been reported. ${ }^{[1]}$ Bowel perforation is seen in $0.01-1 \%$ of all peritoneal shunting procedures, with extrusion of the peritoneal end in about half of these. ${ }^{[2]}$ Extrusions have been described mainly through the anal orifice. ${ }^{[3]}$ The authors describe a rare case of peroral extrusion of the peritoneal catheter in an infant, with only five cases previously reported in literature.

\section{Case Report}

A two-month-old female child with history of neonatal meningitis, presented to us with a progressively increasing head circumference, a tense bulging anterior fontanelle, and an upward gaze paresis. Noncontrast CT scan of the brain showed gross hydrocephalus. A right-sided VPS was done. At discharge, the head circumference had reduced, the fontanelle was lax, and the upward gaze paresis had recovered. A few days later, the child was readmitted for a febrile episode, which responded well to symptomatic conservative treatment.

At eight months of age the child had repeated bouts of vomiting, following which the parents noticed that there was a tube protruding through the mouth. There was no history of fever, excessive crying, or any significant problem preceding this event. On admission to the hospital, she was conscious, had spontaneous eye opening, had no neurological deficits, and the anterior fontanelle was depressed. The distal end of the peritoneal catheter was seen coming out through the mouth with a steady flow of cerebrospinal fluid (CSF) [Figure 1]. The shunt tract was normal with no signs of inflammation. The abdomen was soft and bowel sounds were normal.

Plain radiography showed no displacement of the cranial end of the shunt tube. The peritoneal end was seen exiting the peritoneal cavity via the thoracic cavity in a retrograde manner and coming out through the mouth [Figure 2]. Ultrasound of the abdomen was normal. CSF, aspirated from the shunt chamber, showed 
100 cells, predominantly lymphocytes. It was decided to remove the shunt and decide regarding the need for replacement depending on the presence or absence of infection. At intubation the tube was seen coming out of the esophagus. The cranial incision was opened and the shunt divided below the chamber. The ventricular end and the chamber were removed through this incision. The distal end was eased out through the mouth. The child was maintained on intravenous fluids and antibiotics for thirty six hours. The child was then started on oral feeds, which she tolerated well. She was given cephalosporin antibiotics. The child was discharged at two weeks, at which time she was totally asymptomatic. At 12 months follow up the child remained asymptomatic.

\section{Discussion}

While CSF shunting procedures have significantly lowered the morbidity and mortality due to hydrocephalus, it has been estimated that $40-50 \%$ of children and up to $29 \%$ of adults will experience a failure of the shunt within the first year. ${ }^{[4]}$ Clinical indicators of a probable 'early' (within five months of surgery) shunt failure include nausea, vomiting, irritability, depressed conscious level, erythema, bulging fontanelle, and fluid tracking along the shunt tube; while depressed level of consciousness and loss of milestones

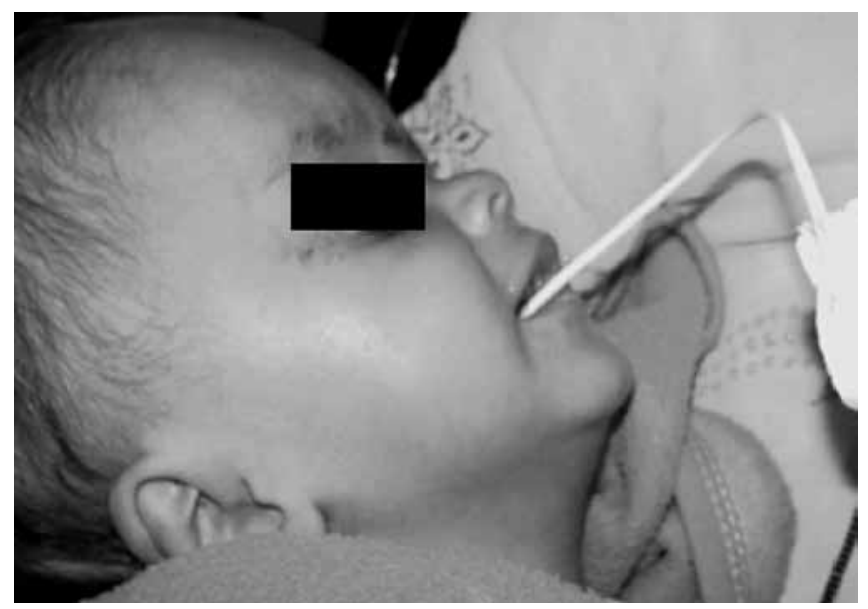

Figure 1: An eight-month-old girl with oral extrusion of the shunt tube are the main indicators in late (later than nine months of surgery) shunt failure. ${ }^{[5]}$ Mechanical complications, including obstruction of the ventricular catheter (63.2\%), obstruction of the peritoneal catheter (23.5\%), migration of the shunt device (8.8\%), disconnection (1.4\%), breakage $(1.4 \%)$, and malpositioning (1.4\%), formed the main type of complication (61.8\%) in the multicentric cooperative study reported by Di Rocco et al. ${ }^{[6]}$ Shunt infections were seen in $22.7 \%$ of patients, while in $11 \%$ it was related to inadequate drainage of CSF. Spontaneous bowel perforation is a rare complication of a VPS, seen in only $0.01-0.07 \%$ of cases. ${ }^{[2,7]}$

Age stands out as the main risk factor for bowel perforation, with about $70 \%$ of patients less than five years of age. ${ }^{[1,2]}$ The incidence of spontaneous bowel perforation is between 0.1 and $1 \%$ of shunted patients. ${ }^{[2,7]}$ The peritoneal end of the shunts, which perforate the bowel, extrude most commonly through the anal orifice $(61.9 \%) \cdot{ }^{[3]}$ Peroral extrusion is extremely rare, with only five cases being reported prior to the present case ${ }^{[1,3,8-10]}$ [Table 1].

All patients with peroral extrusion were below 12 years of age, with our patient being the youngest at eight months [Table 1]. All patients have been female children, in contrast to the slight male preponderance in bowel perforation. ${ }^{[1,3]}$ Shunt tract infection was reported in half

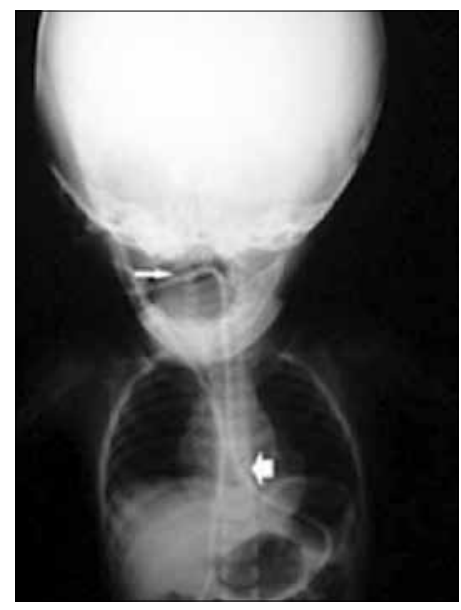

Figure 2: Plain X-ray film showing the track followed by the extruded shunt, perforating probably the stomach or the proximal jejunum and traveling proximally, exiting through the mouth

\begin{tabular}{|c|c|c|c|c|c|c|c|c|}
\hline & $\begin{array}{l}\text { Age } \\
\text { (years) }\end{array}$ & $\begin{array}{c}\text { Sex } \\
(M / F)\end{array}$ & $\begin{array}{l}\mathrm{Gl} \\
\mathrm{Sx}\end{array}$ & $\begin{array}{l}\text { Prior shunt } \\
\text { revision }\end{array}$ & $\begin{array}{l}\text { Shunt tract } \\
\text { infection }\end{array}$ & $\begin{array}{l}\text { Time from } \\
\text { VPS (months) }\end{array}$ & $\begin{array}{c}\text { Site of } \\
\text { perforation }\end{array}$ & $\begin{array}{l}\text { CSF } \\
\text { Inf. }\end{array}$ \\
\hline Griffith et al. & 9.5 & $F$ & No & No & No & 3 & Stomach & Yes \\
\hline Park et al. & 5 & $\mathrm{~F}$ & No & No & Yes & 48 & Stomach & No \\
\hline Fermin et al. & 1.5 & $\mathrm{~F}$ & No & No & No & 6 & Trachea & No \\
\hline Odebode & 1.5 & $\mathrm{~F}$ & No & No & Yes & 6 & Jejunum & No \\
\hline Jimenez et al. & 11 & $\mathrm{~F}$ & Yes & No & Yes & NA & Stomach & No \\
\hline Present case & 0.8 & $\mathrm{~F}$ & No & No & No & 6 & Stomach/Jejunum & No \\
\hline
\end{tabular}

GI Sx - Previous history of gastrointestinal surgery; NA - not available 
the children. Also, significant was the early extrusion following placement of the shunt in all cases except one.

Why the shunt tube should extrude through the mouth in this small number of cases is not clear. It is possible that proximal gut perforation plays a part. Once perforated and lying in the stomach or the jejunum, forceful repeated vomiting and retching may cause the tube to travel into the oral cavity. Three of the five reported children had shunt tract infection, which probably led to inflammation and adherence of the tube to the proximal gut. Whether the seemingly innocuous febrile episode that our patient had within a month of the initial shunt placement was relevant to the development of the bowel perforation is a matter for discussion.

Due to the small number of cases reported, the correct line of management is not certain. The first step in the management should be to look for CSF infection and for shunt tract inflammation. Broad-spectrum antibiotic cover for gut flora should also be started at admission and removal of the tube should be under antibiotic cover. Endoscopic removal of the distal end of the shunt tube, ${ }^{[1]}$ and a laparotomy ${ }^{[3,10]}$ have been done. A major laparotomy is probably unnecessary as the opening in the bowel is small and seals off spontaneously. ${ }^{[1]} \mathrm{It}$ is important that the proximal catheter including the ventricular end be removed through a clean cranial incision. Most patients will need replacement of the shunt device after treatment of the bowel perforation and any infection. Our patient, however, remained asymptomatic not requiring a shunt post perforation. Why she became shunt independent is debatable. The only plausible explanation is that CSF pathways, not yet mature when the initial shunt was placed, had opened up and become functional, making her shunt independent.

Bowel perforation and shunt tube extrusion do not always have a benign course. Park et al. ${ }^{[1]}$ reported $20 \%$ mortality in the 50 cases they reported. The child reported by Griffith et al ${ }^{[9]}$ was the only one with peroral extrusion who died, and also the only child with CSF infection. A low threshold of suspicion is needed to diagnose bowel perforation, as less than $25 \%$ of patients with bowel perforation exhibit signs of peritonitis. ${ }^{[7]}$ Prolonged diarrhea with abdominal symptoms in a shunted patient should warn of a possible perforation. CSF cultures have been found to be positive in 23 of 45 patients with bowel perforation, with Escherichia coli being the most common organism. ${ }^{[7]} \mathrm{A}$ shunted patient presenting with ventriculitis or meningitis due to an enteric organism, should be presumed to be have a silent bowel perforation and should be investigated for the same. It does appear that proximal perforations of the stomach or proximal jejunum are less prone to severe infectious complications than are perforations of the distal intestine like the colon, though there is no evidence for this.

Peroral extrusion of the distal end of a shunt tube is one of the rare complications of VP shunting. It is the end result of a bowel perforation, which by itself is a potentially hazardous complication. This situation needs an individualized, planned approach that includes antibiotics and treatment of CSF infection and the bowel perforation by the treating physician.

\section{References}

1. Park CK, Wang KC, Seo JK, Cho BK. Transoral protrusion of a peritoneal catheter: A case report and literature review. Childs Nerv Syst 2000;16:184-9.

2. Vinchon M, Baroncini M, Laurent T, Patrick D. Bowel perforation caused by peritoneal shunt catheters. diagnosis and treatment. Neurosurgery 2006;58: ONS76-82.

3. Odebode TO. Jejunal perforation and per oral extrusion of a peritoneal shunt catheter. Br J Neurosurg 2007;21:235-6.

4. Wu Y, Green NL, Wrensch MR, Zhao S, Gupta N. Ventriculoperitoneal shunt complications in California: 1900 to 2000. Neurosurgery 2007;61:557-63.

5. Piatt JH Jr, Garton HJ. Clinical diagnosis of ventriculoperitoneal shunt failure among children with hydrocephalus. Pediatr Emerg Care 2008;24:201-10.

6. Di Roceo C, Marchese E, Velardi F. A survey of the first complication of newly implanted CSF shunt devices for the treatment of nontumoral hydrocephalus. Child's Nerv Syst 1994;10:321-7.

7. Satyanarayana S, Wylen EL, Baskaya MK, Nanda A. Spontaneous bowel perforation after ventriculoperitoneal shunt surgery. case report and a review of 45 cases. Surg Neurol 2000;54:388-96.

8. Jimenez Moya A, Penela Velez De Guevara T, Gracia Remiro R, Romero Escos D, Santana Rodriguez C, Reig Del Moral C, et al. Extrusion of a ventriculo-perioneal shunt catheter through the mouth. An Esp Pediatr 2001;54:609-10.

9. Griffith JA, DeFeo D. Peroral extrusion of a ventriculo-perioneal shunt catheter. Neurosurgery 1987;21:259-61.

10. Fermin S, Fernandez-Guerra RA, Sureda PJ. Extrusion of peritoneal catheter through the mouth. Child's Nervous System 1996;12:553-5.

Accepted on 04-03-2009

Source of Support: Nil, Conflict of Interest: None declared. 